\title{
Identification of RNA as a substance responsible for the survival of chick spinal motoneurons in vitro
}

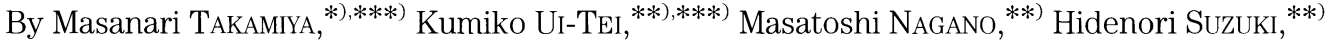 \\ Akinori SuzukI, ${ }^{*)}$ Yuhei MiYATA, ${ }^{* *)}$ and Hiroshi KatAOKA, ${ }^{*}$, ,) \\ (Communicated by Saburo Tamura, M. J. A., March 12, 1999)
}

\begin{abstract}
In our preceding paper, we presented the purification of a chick embryo's muscle-derived substance that prevented spinal neurons from undergoing cell death in vitro. In this study, characterization of this substance by ${ }^{1} \mathrm{H}-\mathrm{NMR}$ spectroscopic analysis and enzymatic inactivation experiments revealed that the substance responsible for the survival of cultured spinal neurons was RNA. For further characterization a modified purification procedure was devised on the basis of the substance being RNA. The finally purified substance showed $\lambda_{\max }$ at $258 \mathrm{~nm}$ and prevented enriched populations of spinal motoneurons from undergoing cell death in vitro, in the same way as the crude muscle extract. These results suggested a novel role of RNA as an intercellular signaling molecule.
\end{abstract}

Key words: RNA; spinal cord; neuron; chick embryo; ${ }^{1} \mathrm{H}-\mathrm{NMR}$.

Introduction. Retrograde trophic signals from synaptic targets are crucial for sculpting the developing nervous system in chick embryos. ${ }^{1)}$ During this crucial stage, neurons are selected to live or die by competing among other neurons for these retrograde trophic signals. ${ }^{1-4)}$ These signals or survival factors were previously deduced to be proteins based on their sensitivity to heat and trypsin. ${ }^{1,3), 4)}$

In our research on survival substances for motoneurons, ${ }^{5)}$ we have purified a substance which exhibits properties very unusual for proteins: It is unusually hydrophilic, it shows a maximum UV absorbance $\left(\lambda_{\max }\right)$ at $258 \mathrm{~nm}$ and gives no amino acid sequence after Edman degradation. ${ }^{5)}$ These properties suggest that the purified substance is unlikely to be a protein. To further characterize this substance, we conducted analyses by ${ }^{1} \mathrm{H}-\mathrm{NMR}$ spectroscopy and enzymatic digestions with RNases or proteinases. The results suggest that the purified substance that prevents chick spinal motoneurons from undergoing cell death in vitro is RNA.

\footnotetext{
*) Graduate School of Agricultural and Life Sciences, The University of Tokyo, 1-1-1 Yayoi, Bunkyo-ku, Tokyo 113-8657, Japan.

**) Department of Pharmacology, Nippon Medical School, 1-1-5 Sendagi, Bunkyo-ku, Tokyo 113-8602, Japan.

***) These authors contributed equally to this study.

†) Correspondence to: H. Kataoka
}

Materials and methods. Materials. Chick embryos were obtained from eggs purchased from a local poulterer (Miyake Eggs, Shizuoka, Japan). Columns used were Capcell-Pak $\mathrm{C}_{18}$ UG120 (Shiseido, Tokyo, Japan), DEAE-5PW (TOSOH, Tokyo, Japan) and Phenyl-Sepharose CL-4B (Amersham Pharmacia Biotech, Sweden). All other HPLC columns were purchased from Senshu Scientific Corporation (Tokyo, Japan). Enzymes used were DNase I (RQ1 RNase-free, Promega, WI, USA), RNase A (Sequence grade, Boehringer Mannheim, Germany) and proteinase $\mathrm{K}$ (RNA grade, GIBCO-BRL, NY, U.S.A.). All other solvents and chemicals were of HPLC grade and were purchased from Nacalai (Kyoto, Japan).

${ }^{1} H$-NMR spectroscopic analysis. The purified substance (approximately $150 \mu \mathrm{g}$ ) was prepared as previously described ${ }^{5)}$ and subjected to analysis by ${ }^{1} \mathrm{H}$ NMR. Finally purified fractions with $\lambda_{\max } 258 \mathrm{~nm}$, corresponding to a single peak detected by UV, were pooled, lyophilized then dissolved in $\mathrm{D}_{2} \mathrm{O}$ (99.8\%, Merck, Germany). ${ }^{1} \mathrm{H}-\mathrm{NMR}$ measurements were conducted with a JEOL (Tokyo, Japan) JNM- $\alpha 600$ spectrometer at $600 \mathrm{MHz}$, at room temperature (27 $\left.{ }^{\circ} \mathrm{C}\right)$.

Modification of purification procedure. On the basis of the expected chemical properties of the biologically active substance from the ${ }^{1} \mathrm{H}$-NMR spectrum (see Results), the purification procedure described in the 
preceding paper ${ }^{5)}$ was modified as follows. Chick skeletal muscles were homogenized in acetone and passed through a paper filter. The recovered acetone-powder was extracted with $2 \%(\mathrm{w} / \mathrm{v}) \mathrm{NaCl}$ solution and centrifuged at $12,000 \times g$ at $4^{\circ} \mathrm{C}$ for $30 \mathrm{~min}$ (the same centrifugation conditions were applied throughout the purification procedure unless stated otherwise). Supernatants were mixed with acetone (30\% final concentration) and centrifuged. Acetone was added once again to supernatants to give a final concentration of $50 \%$ and centrifuged. Precipitates (30-50\% acetone) were directly dissolved in $50 \%\left(\mathrm{NH}_{4}\right)_{2} \mathrm{SO}_{4}$ solution, centrifuged, and supernatants were removed and mixed with an equal volume of phenol:chloroform $(1: 1, \mathrm{v} / \mathrm{v})$ followed by rigorous vortexing and centrifugation at room temperature. The aqueous phase was applied onto a Phenyl-Sepharose CL-4B column and eluted with 50mM Tris-HCl (pH 7.5).

The eluted fraction was subjected to successive preparative HPLC purification steps: 1) Reverse phase HPLC (Capcell-Pak $\mathrm{C}_{18}, 20 \mathrm{mmI} . \mathrm{D} . \times 250 \mathrm{~mm}$ ) eluted with a $100 \mathrm{~min}(8 \mathrm{ml} / \mathrm{min})$ linear gradient of $0-25 \%$ $\mathrm{CH}_{3} \mathrm{OH}$ in $10 \mathrm{mM} \mathrm{CH}_{3} \mathrm{COO}\left(\mathrm{NH}_{4}\right)$ at $\mathrm{pH} 6.5$ (The partially purified substance (PPS) was obtained from this purification step, see Results, Fig. 3). 2) Anion exchange HPLC (DEAE-5PW, $21.5 \mathrm{mmI}$.D. $\times 150 \mathrm{~mm}$ ) eluted with a $120 \mathrm{~min}(5 \mathrm{ml} / \mathrm{min}$ ) linear gradient of $0-0.5 \mathrm{M} \mathrm{NaCl}$ in $50 \mathrm{mM}$ Tris- $\mathrm{HCl}$ at $\mathrm{pH}$ 7.5. 3) Reverse phase HPLC column (Capcell-Pak C 18,20 mmI.D. $\times 250 \mathrm{~mm}$ ) was equilibrated with $100 \mathrm{mM}$ triethylamine-acetate, $5 \%$ (v/v) $\mathrm{CH}_{3} \mathrm{CN}$ at pH 6.75 (buffer A). Linear gradient elution ( $8 \mathrm{ml} / \mathrm{min}, 5-19.25 \% \mathrm{CH}_{3} \mathrm{CN} / 150 \mathrm{~min}$ ) from $100 \%$ buffer A to $100 \%$ buffer B (85 mM triethylamineacetate, $19.25 \%(\mathrm{v} / \mathrm{v}) \mathrm{CH}_{3} \mathrm{CN}$ at $\left.\mathrm{pH} 6.75\right)$ gave a peak with $\lambda_{\max } 258 \mathrm{~nm}$ in the UV elution profile and the corresponding fraction had $38-40 \%$ of the biological activity recovered through this HPLC step (based on the results from two independent and identical purifications conducted with skeletal muscles). This fraction was used in the special bioassays (see below).

Enzymatic inactivation of partially purified substance (PPS) by RNase $A$ and proteinase $K$. Samples were prepared from eluted fractions in the first preparative HPLC purification step (reverse phase Capcell-Pak $\mathrm{C}_{18}$ ). The biologically active fraction that corresponded to the most prominent peak in the elution profile ( $\lambda_{\max } 258 \mathrm{~nm}$ ) was enzymatically digested with 10 $\mathrm{U}$ RNase A or $4 \mathrm{U}$ proteinase $\mathrm{K}$. One aliquot (1.66 g skeletal muscle equiv.) received distilled water but no enzyme (termed "control") and another aliquot was left untreated and maintained at $4{ }^{\circ} \mathrm{C}$ (termed "original"). The samples treated with RNase A, proteinase $\mathrm{K}$ and the control sample were incubated at $37^{\circ} \mathrm{C}$ for 3 hours. To remove the digestive enzymes, each sample was subjected to reverse phase VP-318 (4.6 mmI.D. $\times 150 \mathrm{~mm}$, Senshu Pak, Tokyo, Japan) analytical HPLC purification after the incubation. Flow-through fractions and eluted fractions with $\lambda_{\max } 258 \mathrm{~nm}$ were pooled and assayed.

Preparation of crude muscle extract (CMX) from chick embryos. Crude muscle extract (CMX) was prepared from skeletal muscle of 18-day- and 19-day-old chick embryos by homogenization in $2 \%(\mathrm{w} / \mathrm{v}) \mathrm{NaCl}$ solution and ultracentrifugation at $150,000 \times g$ at $4{ }^{\circ} \mathrm{C}$ for 15 min. Supernatants were suspended in equal volumes of phenol:chloroform:isoamyl alcohol (25:24:1, v/v) and centrifuged at $19,000 \times g$ for $10 \mathrm{~min}$ at $4^{\circ} \mathrm{C}$. The upper aqueous layer ( $0.1 \mathrm{~g}$ skeletal muscle equiv.) was recovered and assayed (see Results, Fig. 2).

In vitro bioassay. Biological activity was assayed throughout the purification procedure using primary cultured spinal neurons. The finally purified substances were subjected to a special bioassay using enriched populations of primary cultured spinal motoneurons (special bioassay). In both in vitro bioassays, neuron cultures were prepared according to the previously described protocol. ${ }^{5)}$ All samples were assayed in triplicate at each of three different concentrations. The number of surviving neurons were counted after each treatment and compared to the number of neurons surviving after treatment with the maximal effective dose of CMX (10 mg skeletal muscle equiv.)

Results. The ${ }^{1} \mathrm{H}-\mathrm{NMR}$ spectrum of the purified substance $^{5)}$ showed broadened peaks characteristic of polymers (Fig. 1). Signals assigned to protons of $\beta$-Dribose and purine and pyrimidine bases were observed, ${ }^{7), 8)}$ whereas signals assigned to $2^{\prime} \mathrm{H}$ and $2^{\prime \prime} \mathrm{H}$ of $2^{\prime \prime}$-deoxy- $\beta$-D-ribose of DNA were not observed (Fig. 1). These results indicated that the purified substance was a polymer of ribonucleotides (RNA).

Next, crude muscle extract (CMX) was extracted with phenol/chloroform/isoamyl alcohol and subjected to the bioassay (Fig. 2). Extraction of CMX with phenol/chloroform/isoamyl alcohol did not significantly affect its ability to maintain the survival of cultured spinal neurons at each tested dose (Fig. 2), an indication that the biologically active substance is not a protein. This corroborates the ${ }^{1} \mathrm{H}-\mathrm{NMR}$ analysis results which showed that the purified substance was RNA (Fig. 1).

On the basis of the substance being RNA, the pre- 


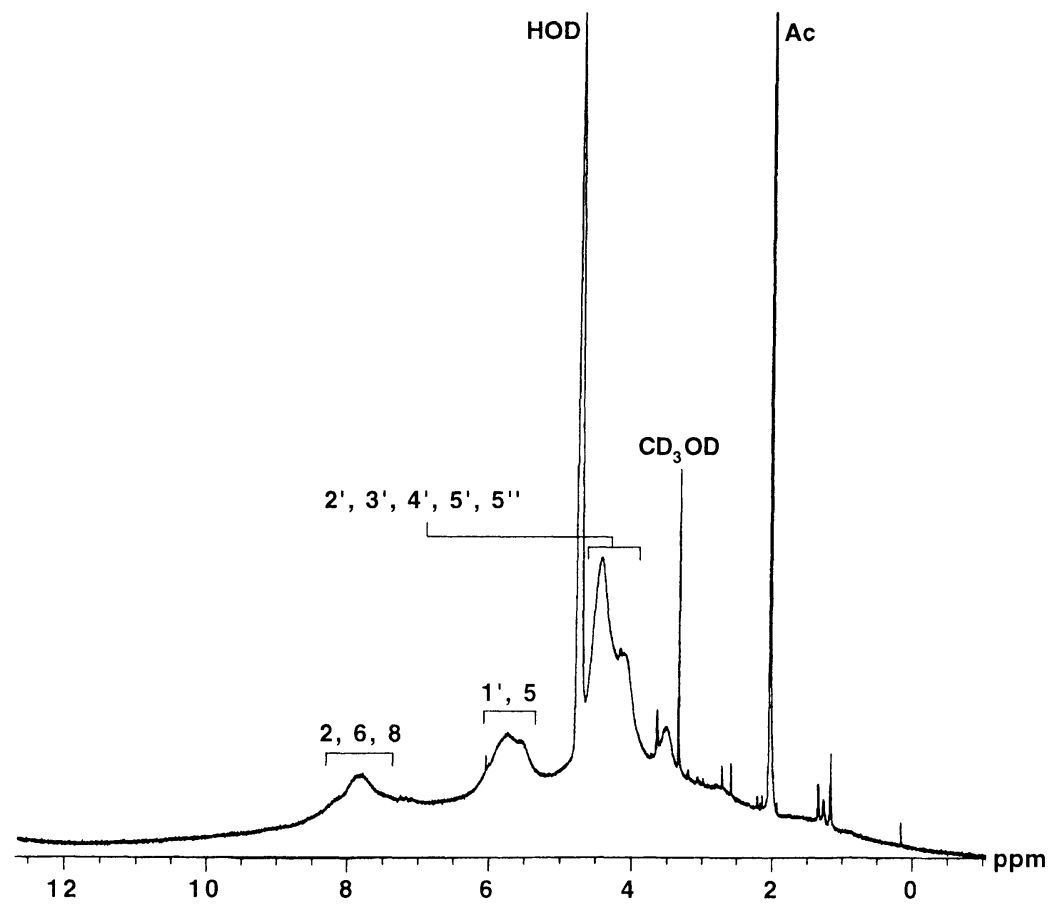

Fig. 1. $\quad{ }^{1} \mathrm{H}-\mathrm{NMR}$ spectroscopic analysis. The $600 \mathrm{MHz}{ }^{1} \mathrm{H}-\mathrm{NMR}$ spectrum (measured in $\mathrm{D}_{2} \mathrm{O}$ ) of the finally purified substance is shown. Numbers indicate the assignments that can be made based upon the expected chemical shifts: $1^{\prime}, 2^{\prime}, 3^{\prime}, 4^{\prime}, 5^{\prime}$ and $5^{\prime \prime}$ correspond to $1^{\prime} \mathrm{H}$, $2^{\prime} \mathrm{H}, 3^{\prime} \mathrm{H}, 4^{\prime} \mathrm{H}, 5^{\prime} \mathrm{H}, 5^{\prime \prime} \mathrm{H}$ of $\beta$-D-ribose, respectively; 5 and 6 correspond to $5 \mathrm{H}$ and $6 \mathrm{H}$ of pyrimidine bases, respectively; 2 and 8 correspond to $2 \mathrm{H}$ and $8 \mathrm{H}$ of purine bases. The abbreviations $\mathrm{HOD}, \mathrm{Ac}$ and $\mathrm{CD}_{3} \mathrm{OD}$ indicate the signals due to the residual $\mathrm{HOD}$ in ${ }^{2} \mathrm{H}_{2} \mathrm{O}$, ammonium acetate and methyl alcohol, respectively, which were used as elution buffers for HPLC. Chemical shifts are expressed in parts/million (ppm).

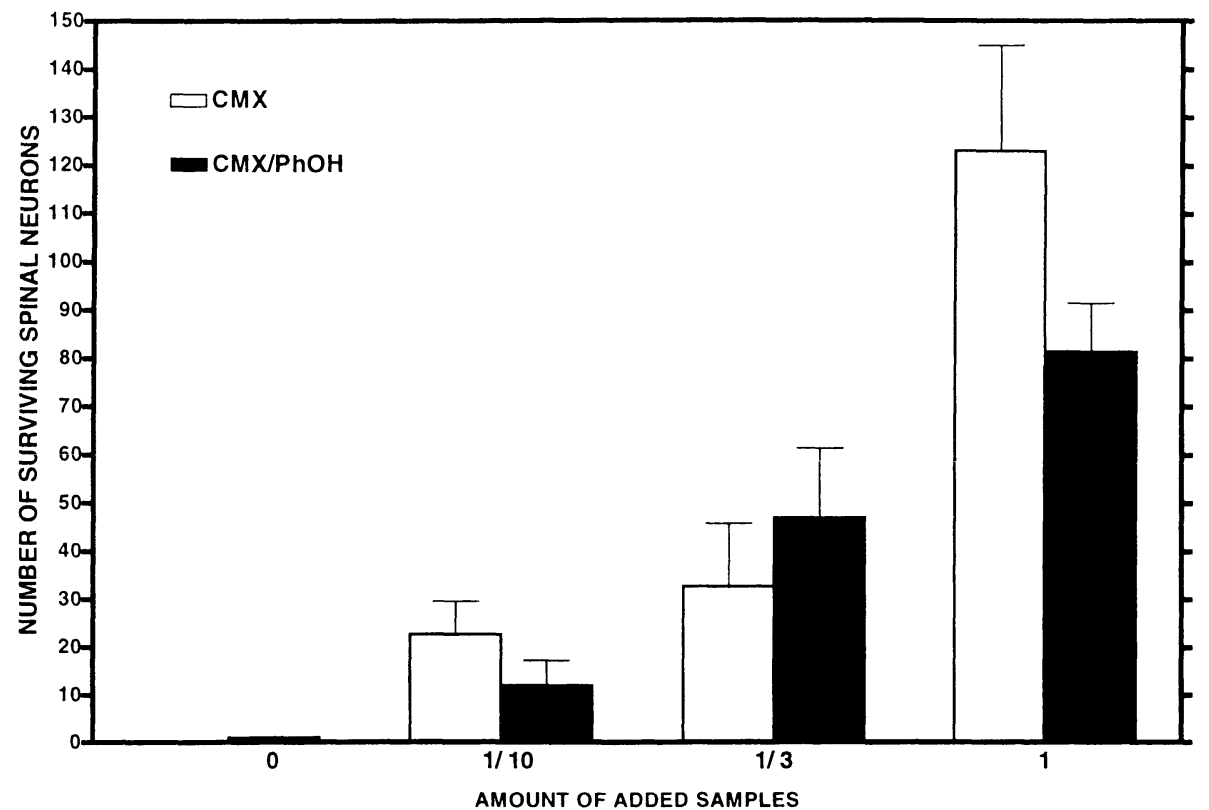

Fig. 2. Recovery of the biologically active substance following phenol/chloroform/isoamyl alcohol extraction of crude muscle extract (CMX). Numbers of surviving spinal neurons (mean \pm S.D.) were counted in a predetermined rectangular area $\left(895 \times 1340 \mu \mathrm{m}, 1.2 \mathrm{~mm}{ }^{2}\right)$. The amount of added samples is expressed as an index number: 1 equals $10 \mathrm{mg}$ skeletal muscle equivalent. Two way analysis of variance revealed that: 1) The biologically active substance had been partitioned into the aqueous phase (CMX/PhOH) after phenol/chloroform/isoamyl alcohol extraction $(\mathrm{P}=0.25)$. 2) Biological activity was dependent on the amount of added samples $(\mathrm{P}<0.05)$. 


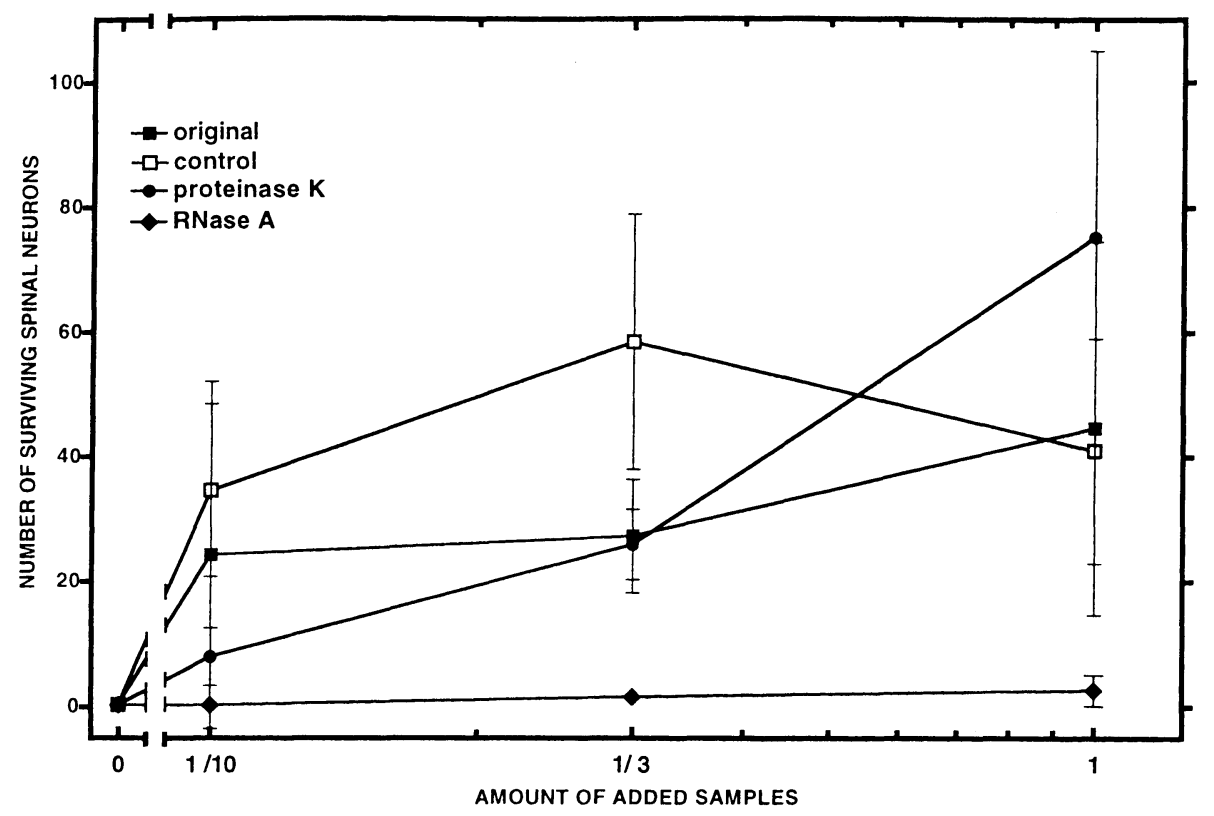

Fig. 3. Enzymatic inactivation of a partially purified substance (PPS). Partially purified substance (PPS) was treated with proteinase K and RNase A, respectively, and incubated at $37^{\circ} \mathrm{C}$ for 3 hours followed by HPLC purification and addition to spinal neuron cultures (Original: untreated PPS, Control: PPS incubated with distilled water at $37^{\circ} \mathrm{C}$ for 3 hours). Numbers of surviving spinal neurons (mean \pm S.D.) were counted after a 2 day culture without serum. The amount of added samples is expressed as an index number: 1 equals 166 mg skeletal muscle equivalent. Two way analysis of variance revealed that: 1) The effects of treatments were significant $(\mathrm{P}<0.05)$ and 2) The amount of added samples significantly altered the results $(\mathrm{P}<0.05)$. One way analysis of variance revealed no statistically significant differences among the four samples at doses of $1 / 10$ equiv. $(\mathrm{P}>0.05)$ and statistically significant differences between proteinase $\mathrm{K}$ and RNase $\mathrm{A}$ at a dose of 1 equiv. $(\mathrm{P}<0.05)$.

viously published ${ }^{5)}$ purification procedure was modified by introducing phenol/chloroform extraction as a purification step. The partially purified substance (referred to as PPS) obtained by this modified purification procedure was examined for its sensitivity to RNase treatment. RNase A treatment completely abolished the biological activity of PPS (Fig. 3). In contrast, treatment with proteinase $\mathrm{K}$ had no significant effect on the biological activity of PPS (Fig. 3). These results suggest that the substances responsible for biological activity in the bioassay using spinal neurons is not a protein but an RNA molecule.

To examine the effect of the purified RNA on the survival of enriched population of spinal motoneurons in vitro, samples obtained from the modified procedure were assayed in the special bioassay. The results showed that purified substance (384 ng RNA; $240 \mu \mathrm{g}$ skeletal muscle equiv.) in $1 \mathrm{ml}$ of culture medium can maintain the survival of $110 \pm 3.2 \%$ of CMX-treated motoneurons (mean \pm SEM) and a value of $39 \pm 4.8 \%$ of CMX-treated motoneurons (mean $\pm \mathrm{SEM}$ ) was obtained at a dose of $38.4 \mathrm{ng}$ of RNA .

Discussion. Spectroscopic analysis by ${ }^{1} \mathrm{H}-\mathrm{NMR}$ revealed that the major component of the purified biologically active substance ${ }^{5}$ was RNA (Fig. 1) and a modified purification procedure was adopted based on the observation that the substance was effectively purified by the extraction with phenol/chloroform/isoamyl alcohol (Fig. 2). Enzymatic digestion of PPS samples, obtained by a modified purification procedure, with RNase $\mathrm{A}$ and proteinase $\mathrm{K}$ further confirmed that the biologically active substance is RNA (Fig. 3).

Proton-NMR spectra of DNA are distinguishable from those of RNA on the basis of proton signals of ribose moieties. ${ }^{8)}$ In DNA the signals of $2^{\prime} \mathrm{H}, 2^{\prime \prime} \mathrm{H}$ of $2^{\prime \prime}$-deoxy- $\beta$ D-ribose have chemical shift $(\delta)$ ranging from 1.8 to 3.0 $\mathrm{ppm},{ }^{8)}$ whereas no obvious signals were detected within this region (Fig. 1). These results further confirm that the purified substance is RNA and not DNA.

All the features of the purified substance lead us to the conclusion that it is a strand of RNA (polyribonucleotides) and not a single ribonucleotide. For example: 1) The biological activity was abolished by RNase A treatment, 2) ${ }^{1} \mathrm{H}-\mathrm{NMR}$ spectrum showed broadening peaks indicative of a polymer, 3) The substance was heat labile $\left(96^{\circ} \mathrm{C}, 5 \mathrm{~min}\right)$, whereas single ribonucleotides are 
stable to heat treatment. ${ }^{9)}$ 4) The molecular weight of the substance was estimated to be 17,000-47,000 (by gel permeation chromatography, data not shown).

The partially purified sample (PPS) appeared to be rather insensitive to endoribonuclease digestions (RNase $\mathrm{T}_{1}, \mathrm{U}_{2}$, B. cereus and Phy $\mathrm{M}$, data not shown), and required relatively large amounts of RNase A (10 units, Fig. 3) to be completely inactivated. On the other hand, exonuclease digestions effectively abolished the biological activity even in a small dose (0.04 unit of nuclease $\mathrm{P}_{1}$, data not shown). Resistance of PPS to endoribonuclease treatment may be due to the potential secondary structures formed within the RNA molecules, which would also endow the biologically active substance with greater stability towards RNase A treatment or degradation during the series of purification steps that were employed.

Initial experiments did not support the idea that the biologically active substance was RNA. For example, we observed that the CMX-contained biologically active substance was significantly degraded by trypsin treatment and similar results were observed with baker's yeast tRNA as assessed by HPLC elution profiles and polyacrylamide gel electrophoresis (data not shown). However, we believe this to be an artifact produced by the presence of trace amount of exonucleases in the commercially available trypsin preparations that were used.

In the modified purification procedure, the fraction that possessed $>50 \%$ of the biological activity recovered through each purification step were chosen for further purification. This indicates that the purified RNA occupied a large proportion in CMX-derived biologically active substances. Although further studies will be required to determine the potential role of this trophic entity in ovo during the period of naturally occurring cell death $^{2)}$ of embryonic spinal motoneurons, the observation that RNA can prevent spinal motoneuron from undergoing cell death even at small doses (384 ng $\mathrm{RNA} / \mathrm{ml}$ ) opens up a new realm of possibilities for RNA as an intercellular signaling molecule.

Acknowledgements. We thank Ms. Sachie Jitsukawa for her excellent technical assistance, and to Dr. Skarlatos G. Dedos and Ms. Jennifer S. Ito for their valuable comments. This work was supported by grants from the Ministry of Education, Science, Sports and Culture of Japan (Nos. 10161210, 09670109 and 10876025 to K. U-T., H. S., and H. K., respectively).

\section{References}

1) Oppenheim, R. W., Haverkamp, L. J., Prevette, D., McManaman , J. L., and Appel, S. H. (1988) Science 240, 919-922.

2) Oppenheim, R.W. (1991) Annu. Rev. Neurosci. 14, 453-501.

3) Smith, R.G., McManaman, J., and Appel, S.H. (1985) J. Cell. Biol. 101, 1608-1621.

4) Smith, R.G., Vaca, K., McManaman, J., and Appel, S. H. (1986) J. Neurosci. 6, 439-447.

5) Ui-Tei, K., Takamiya M., Nagano, M., Suzuki, H., Suzuki, A., Kataoka, H., and Miyata, Y. (1999) Proc. Japan Acad. 75B, 54-58.

6) In The Merck Index; twelfth edition (1996), NJ, U.S.A.

7) Pouchert, C. J., and Campbell, J. R. (1974) In The Aldrich Library of NMR Spectra. Aldrich Chemical Company, WI, U.S.A.

8) Wüthrich, K. (1986) In NMR of Proteins and Nucleic Acids. John Wiley \& Sons, New York. 